\title{
Development of a 3-D Graphical Database System (GDS) for Landfill Operations Using GPS
}

\author{
Hui-Ping Tserng ${ }^{a}$, Jeffrey $S$. Russell ${ }^{b}$, and Dharmaraj Veeramani ${ }^{c}$
}

a Ph.D. Candidate and Grad. Res. Asst., Dept. of Civil \& Environ. Engrg., University of Wisconsin Madison, Madison, WI 53706.

b Assoc. Prof., Dept. of Civil \& Environ. Engrg., University of Wisconsin - Madison, Madison, WI 53706.

c Asst. Prof., Dept. of Industrial Engrg., University of Wisconsin - Madison, Madison, WI 53706.

Abstract: Landfill space is an important commodity for landfill companies. It is desirable to develop an efficient tool to assist space management and monitor space consumption. When recyclable wastes or particular waste materials need to be retrieved from the landfill site, the excavation operations become more difficult without an efficient tool to provide waste information (i.e., location and type). In this paper, a methodology and several algorithms are presented for developing a 3-D Graphical Database System (GDS) for landfill operations. 3-D GDS can not only monitor the space consumption of a landfill site, but can provide exact locations and types of compacted waste which would benefit the landfill excavation operations or recycling programs.

\section{Introduction}

Unused landfill space is an important commodity for public or private landfills worldwide. Since landfill space is sold by the weight of waste materials at the landfill gate, waste density is a significant factor influencing landfill overhead. If the space consumption for various types of waste materials can be monitored, a better space management can be achieved by deciding a proper tonnage fee (waste is charged by the ton in USA, i.e., $\$ 0.50$ to $\$ 2.0 \mathrm{lyd}^{3}$ ). Improving landfill space management can lead to dramatic financial benefits, while poor space management will conversely cause financial erosion. Thus, it is desirable to develop effective tools for landfill space management and monitoring.

Most of the recyclable solid wastes (coal ash and sludge, construction debris, demolition debris, etc.) that do not have an economical and efficient recovery or recycle program are usually disposed in a sanitary landfill. When new recovery programs are developed, the ability to retrieve buried recyclable materials from landfill sites will provide both a financial and environmental benefits by saving landfill space. However, since no convenient tool or system for recording exact waste location and type in landfill sites is currently available in the conventional landfilling operations, it is difficult and inefficient for the recovery process to excavate a particular waste from the landfill site. Hence, it is necessary to develop a system for recording the information (i.e., location, type, and source) of waste in landfill sites.

In this paper, a 3-D Graphical Database System (GDS) is proposed for solid waste management of landfill sites that will improve and assist the recovery program as well as monitor the space usage of landfill sites. The proposed system will not only improve the productivity of the recovery process, but will also provide a visible 3-D landfill layout that will facilitate the landfill space management in daily operations.

\section{Background}

A limited amount of research has been done in the area of automation and robotics for hazardous waste sites. Much of this research is related to the hazardous waste handling and the removal of buried hazardous, such as the development of robotic soil sampler [1,2], a robotic arm to grasp and manipulate the hazardous waste [3] and a feasibility analysis of automation for hazardous waste remediation [4].

As for the spreading and compaction of waste and cover material at a landfill site, automation of processes requires an efficient operation planning system to 
generate an area-covering path that facilitates autonomous movement of compactors. Tserng et al. [5,6,7,8] and Kunigahalli et al. [9] developed an automated system to assist in the design of landfill cells and the generation of an area covering path for an autonomous compactor for smooth surfaces. Typically, a given landfill site (see Figure 1) can be partitioned into cells using a probabilistic model for waste generation [10]. The configuration of the landfill site is partitioned into a quadtree data structure by employing a recursive spatial decomposition technique. A recursive subdivision of each cell into monominoes allows the system to automatically deal with any deviation in the actual volume of waste. Within the monomino, the motion path of the compactor can be made by several motion models including: Straight-Up, Straight-Down, and ZigZag motion models. Since there are uncertain job-site conditions at landfill sites such as changing profiles and rough surfaces, the balance of the autonomous compactor must be real-time controlled. In addition, the landfill should be maintained to ensure a smooth surface [8].

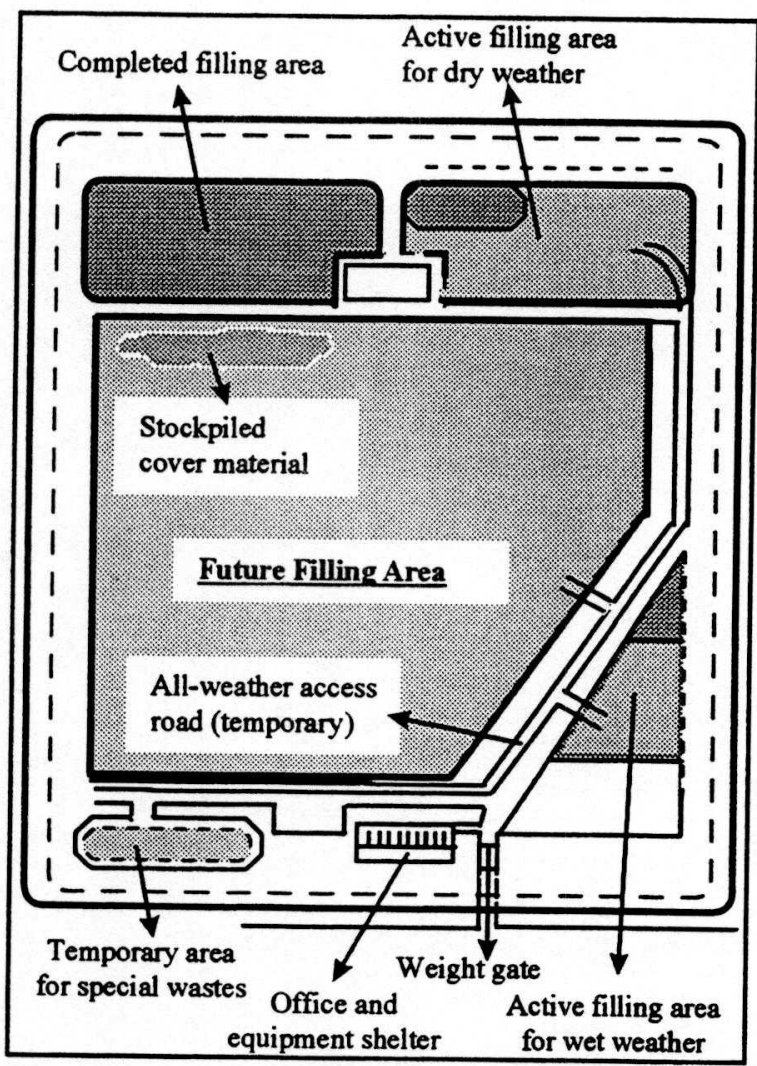

Figure 1: Problem statements and Methodology

\section{Research Objective}

In the proposed system, the original landfill configuration can be roughly obtained from the CAD- based file. The exact profiles and surface conditions of current the landfill site can be measured using Global Positioning System (GPS). Mounting the GPS receiver on a truck or ATV allows measurement to be made while moving through the completed, active, and future filling site (see Figure 1). After the first-run setup, GPS receivers as installed on one or two major compactors, allowing surface conditions to be updated in real-time during the waste compaction process.

As for space management, landfill space is partitioned recursively into small working places using the Octree algorithm. The entire landfill site can be represented and managed by an Octree data structure. The location and type of waste is recorded into properties of Octree nodes. Thus, space consumption and waste information can be obtained easily by traversing the Octree data structure. The resulting real-time graphical information of the entire landfill site can be used for solid waste management and recorded for assisting the recovery process of buried recyclable waste in the future.

The objective of this paper is to develop a 3-D GDS for solid waste management of a landfill site that will improve and assist the recovery program as well as monitor space usage. The proposed system will not only improve the productivity of the recovery process, but will also provide a visible 3-D landfill layout that will facilitate the landfill space management in daily operations.

\section{Major Issues for Developing a 3-D GDS}

The development and use of a 3-D GDS for solid waste management in landfill sites requires the investigation of several important issues including: (1) the development of a space model by the establishment and integration of a computer-aided design/ computeraided construction (CAD/CAC) model and a sensing and mapping system; and (2) space model management. This paper will focus upon these two issues using the research methodology outlined in Figure 2.

\subsection{Space Model Development}

Developing the space model for 3-D GDS includes two major problems: (1) developing a proper geometric model for a landfill site and (2) using the mapping and positioning system to update the landfill geometric model in real-time. 


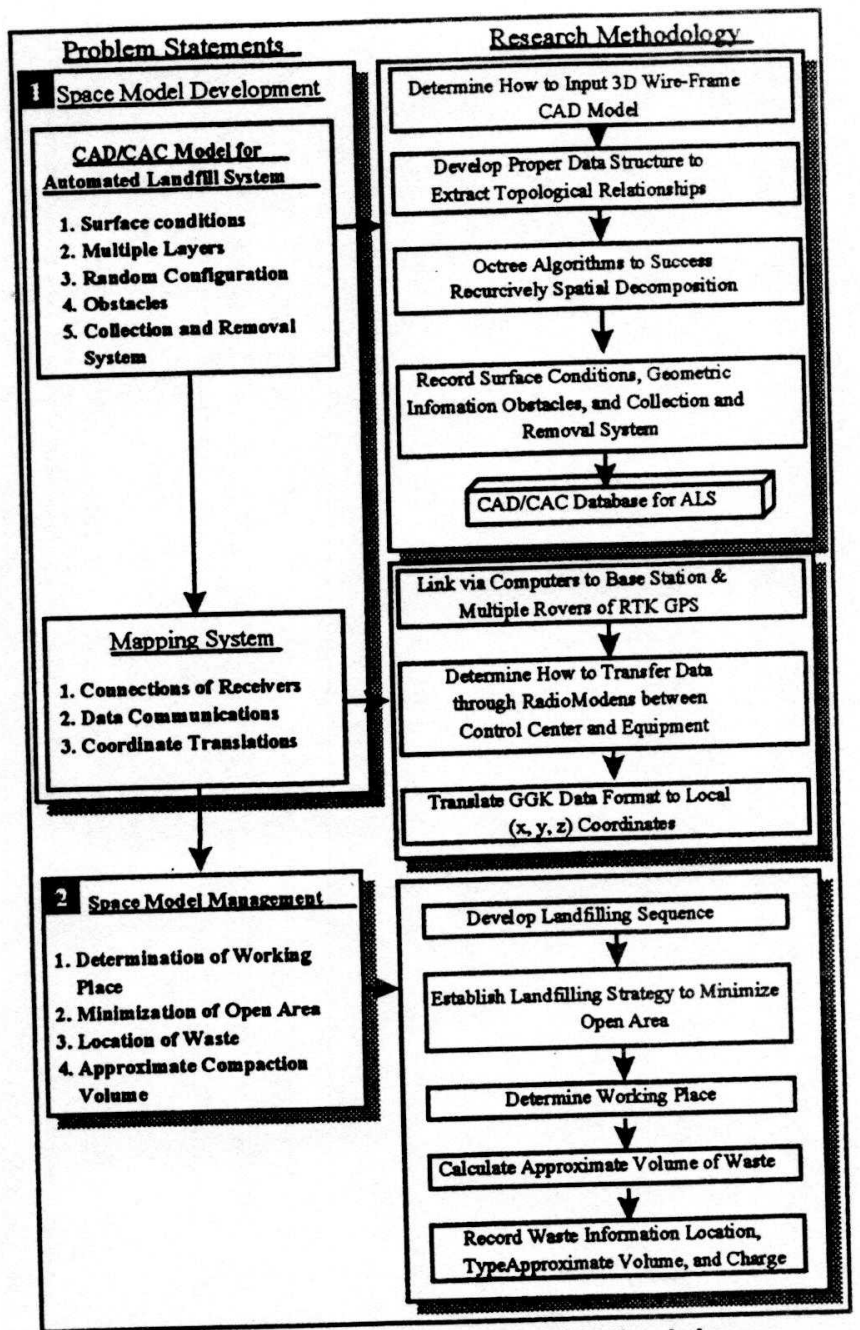

Figure 2: Major Issues and Methodology

\subsubsection{Development of a Proper Geometric Model}

The development of a suitable geometric modeling system for modeling landfills is the first task. In general, three types of landfill operations are used: the trench method, the area method, and the depression method (see Figure 3). In each method, the landfill site is constructed in multiple layers. Each landfill configuration usually has a random shape which depends on the original terrain. This proposed geometric model should be able to deal with different 3-D shapes for each layer. The geometric model of the landfill also needs to include the leachate collection and removal system (see Figure 4) which will affect the operation sequence. Since there are uncertain job-site conditions at landfill sites (i.e., changing profiles and rough surface), understanding surface conditions for the geometric model is an important feature that assists space management and improves the safety for crews in landfilling operations. In the proposed system, the geometric model will face how to: (1) efficiently extract the demand information, (2) record the surface conditions into data structure, (4) deal with random 3-D shape of the landfill configuration, (5) deal with multiple layers, (6) record the configuration of leachate collection and removal system, (7) record locations, types, and sources of all waste materials.

\subsubsection{Mapping and Positioning System}

Mapping and positioning technologies have recently shown great promise for application in field automation. Mapping and positioning technologies should be able to input real-time surface conditions of the landfill site into the landfill space model. In addition, this mapping system will track the positions of landfill equipment for the purpose of space model management as well. The mapping system should be linked to the space management system to provide information on the space occupied by landfill vehicles. Since the landfilling process is an outdoor operation, GPS receivers can easily receive the radio waves from satellites. A Standard GPS can offer an economic and efficient way to obtain the real-time positions of landfill equipment with an accuracy of ten meter. For more precise accuracy, the Differential GPS (DGPS) and Realtime Kinematic GPS (RTK GPS) can improve GPS accuracy to one meter and one centimeter, respectively. Therefore, some of the issues we have to investigate are: (1) Standard GPS, (2) DGPS, (3) RTK GPS, (4) connection system among computers, base station, and rovers, (5) communication through radio modens between control center and equipment, (6) translation of GGK data format to local coordinates, and (7) terrain database system.

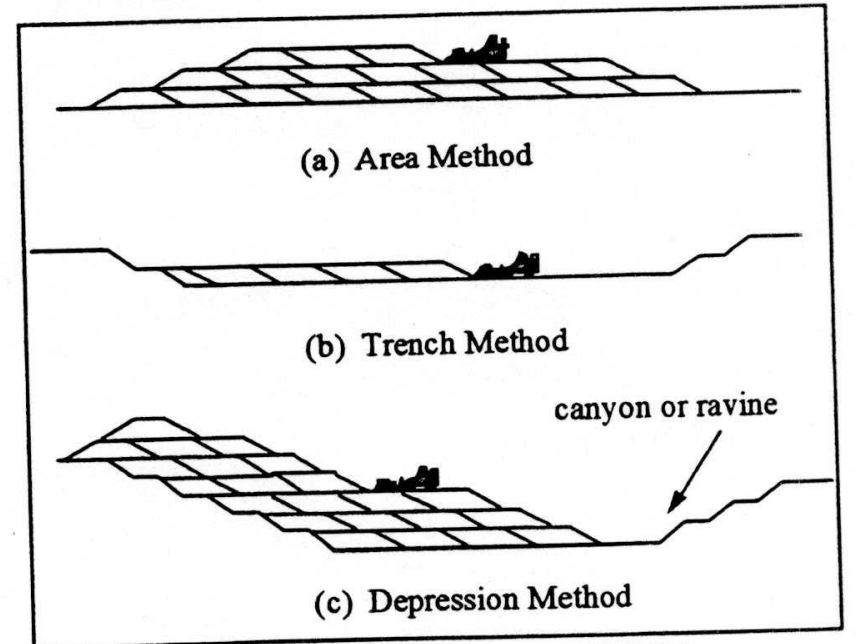

Figure 3: Side View of Landfill Site 


\subsection{Space Model Management}

For assisting the recovery propose, similar recyclable materials should be stored together in the landfill site. Since there are several types of recyclable material that may be stored in one landfill site, it is important to develop an efficient strategy to store them. This strategy will have to consider the productivity of landfilling operations as well as sufficient cover material and landfill space. In general, space model management pertains to allocating work space to resources associated with work tasks in a schedule as it changes over time. From an economic point of view, space management must be optimized. Since unused landfill space is the real commodity for landfill companies. Additionally, solid waste operations are a dynamic process where many pieces of equipment and crews move about. Unless properly addressed, congestion could seriously hamper production and possibly waste landfill space. Proper space scheduling and management offers substantial benefits in terms of expanding the life of the landfill site as well as avoiding the congestion and conflict of multi-vehicle operations.

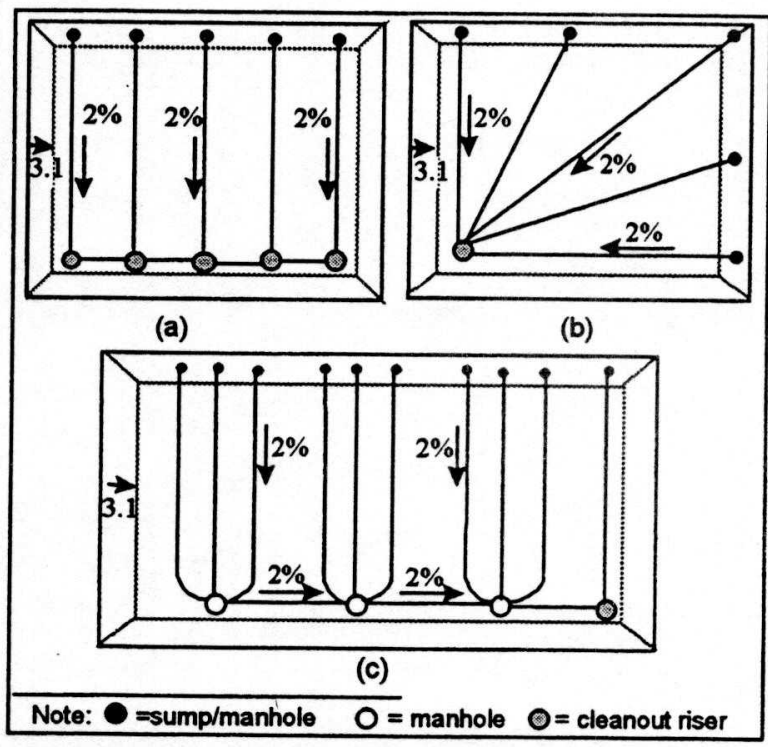

Figure 4: Leachate Collection and Removal System [11]

\section{Methodology}

The framework and methodology developed for a 3D GDS for landfill operations is shown in Figure 2. The figure describes the implementation of a geometric model used to partition the landfill site and shows the development of a mapping system established to achieve the real-time measurement of landfill space. The following sections contain detailed descriptions and algorithms pertaining to the research methodology: (1) GPS technology to achieve real-time space measurement, (2) Link data via computers to GPS base station and rovers, (3) Managing landfill space using octree algorithm, and (4) Octree Coding system.

\subsection{GPS Technology to Achieve Real-time Space Measurement}

As previously described, the waste density is an important factor influencing the landfill overhead. The weight of waste can be measured at the weight gate at the landfill entrance. If occupied space of waste is also obtained, the waste density can be easily calculated (waste density is roughly around $1,000 \mathrm{lbs} / \mathrm{yd}^{3}$ [12]). In general, there are three major types of survey technologies that can be applied to measure occupied landfill space: (1) ground surveying, (2) aerial surveying, and (3) Global Positioning System (GPS). Since ground surveying is the conventional surveying technology and equipment is easily rented or purchased, ground surveying is still common in recent landfill operations. Ground surveying not only has high accuracy, but is not limited by weather or ground surface conditions. The primary disadvantage is that ground survey requires significant personnel and technical skills to achieve this accuracy. Frequent ground surveys will require costly periodic outsourcing or an increase in landfill personnel. Furthermore, the setup time may lengthened due to line of sight restrictions caused by rough surface conditions. The benefits and disadvantages of ground surveying, aerial surveying, and several GPS technologies are listed in Table 1.

Table 1: Evaluations of Survey Methods

\begin{tabular}{|c||c|c|c|c|}
\hline & Cost & Time & Accuracy & $\begin{array}{c}\text { Personnel } \\
\text { required }\end{array}$ \\
\hline \hline Ground Surveying & low & $2-3$ days & $\begin{array}{c}6 \mathrm{~cm} \\
(0.5 \mathrm{ft})\end{array}$ & $\begin{array}{c}2-3 \\
\text { crews }\end{array}$ \\
\hline $\begin{array}{c}\text { Aerial } \\
\text { Surveying }\end{array}$ & high & $2-4$ weeks & $\begin{array}{c}12 \mathrm{~cm} \\
(1 \mathrm{ft})\end{array}$ & $\begin{array}{c}\text { need } \\
\text { outsources }\end{array}$ \\
\hline Standard GPS & low & real-time & $10-100 \mathrm{~ms}$ & 1 (or not) \\
\hline Differential GPS & high & real-time & $1-10 \mathrm{~ms}$ & 1 (or not) \\
\hline RTK GPS & high & real-time & $1 \mathrm{~cm}$ & 1 (or not) \\
\hline
\end{tabular}

require one hour setup.

Aerial surveys begin with photographs taken during flights over the area to be mapped, and these images are used to produce computer-aided design (CAD) model. The CAD-based model is then used to calculate topographical changes and waste volumes put in place. Based on this volume and the tonnage of waste crossing the scale, an in-situ density of waste is calculated. Metro Waste Authority (MWA) reviewed aerial photography as 
a convenient way of providing an updated base map, mainly for use when submitting the triennial permit renewal application. However, aerial surveying was not seen as a major tool for conducting ongoing operational and landfill space monitoring due to expense (around $\$ 15,000$ [12]) and the requirement for equipment that almost landfill companies did not own. The other major disadvantage is that processing of data may require two to four weeks, resulting untimely space management.

GPS was developed by the U.S. Department of Defense (DOD) as a worldwide navigation and positioning resource for both military and civilian use. GPS is based upon a constellation of 24 satellites orbiting the earth in 12-hour orbits $20,000 \mathrm{Km}$ above the earth's surface. These satellites work as reference points for the GPS receivers on the ground to triangulate their position. Receivers measure the distance between the satellite's and their antennae. By measuring the travel time of signals transmitted from the satellites, a GPS receiver on the ground can determine its distance from each satellite. These distances are then used together with knowledge of the satellites' positions to compute the location of the receivers' antennae on the ground [13]. GPS can be classified into three types: (1) Standard GPS, (2) Differential GPS, and (3) Real-time Kinematic (RTK) GPS.

Standard GPS, with an accuracy of about 100meters, can only be operated with one receiver. Differential GPS (DGPS), an enhancement of Standard GPS, can increase the working accuracy (about one meter) of regular GPS measurements. It does so by continually sensing erroneous satellite signals and ensuring that such signals are ignored by the receivers [14]. DGPS requires at least two receivers for a base station and a rover. The base station will detect any erroneous satellite data and tell all rovers using its corrections not to use that satellite's data. RTK GPS receivers employ two or more receivers to achieve accuracy at the centimeter level. Each RTK GPS receiver tracks the $\mathrm{Ll}$ Coarse/Acquisition (C/A) code and full cycle $\mathrm{L} 1 / \mathrm{L} 2$ carrier. $\mathrm{L} 1$ and $\mathrm{L} 2$ is the primary and secondary L-band Carrier used for GPS satellites to transmit satellite data, respectively. C/A doe is a pseudo-random noise code modulated onto a GPS satellite's L1 signal. Carrier-phase measurements contain integer phase ambiguities that must be correctly resolved in order to obtain the highest precision. RTK GPS receivers use On-The-Fly (OTF) ambiguity resolution techniques to acquire integer phase ambiguities while the receiver is moving. Figure 4 shows the real-time landfill space measurement using RTK GPS. A minimum of 5 satellites are required for initialization, which normally takes under 2-10 minutes.
Once initialized, a minimum of 4 satellites must be tracked to avoid re-initialization of the system [15].

After the initial setup (approximately 1 hour) of RTK GPS equipment, the GPS antennae can be mounted on a compactor, or other mobile equipment. On-The-Fly measurements are then made while moving throughout the site. The major advantages of RTK GPS are centimeter-level accuracy, short setup time, real-time data acquisition, and no requirement of horizontal line of sight. Ground surveys are sufficiently accurate, but take too long to get the necessary data and need several skilled crews. Though aerial surveys are faster to setup and measure, they take too long to process data and can not generate the required accuracy. RTK GPS can overcome the performance drawbacks of each of these two systems, but does carry its one major disadvantage of its high initial capital cost $(\$ 45,000-\$ 60,000)$. However, extending RTK GPS to other landfill operations (i.e., gas pile installation, construction survey and grade stake placement, equipment tracking and productivity measurement, etc.) would make RTK GPS a cost effective option.

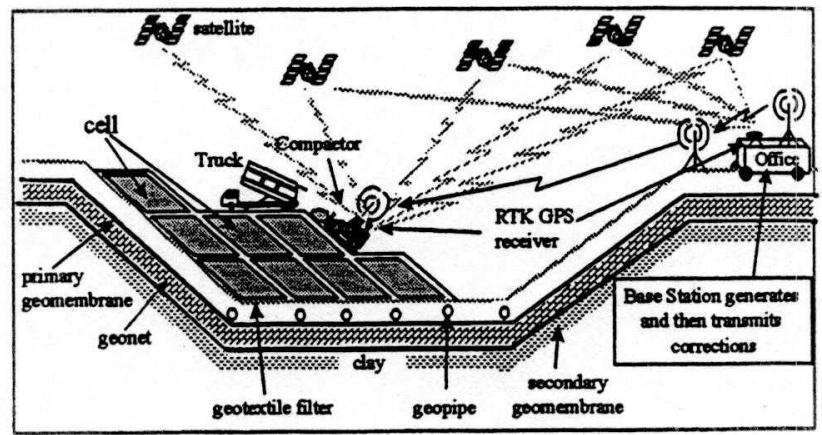

Figure 5: RTK GPS

\subsection{Link Data via Computers to GPS Base Station and Rovers}

The basic components of RTK GPS include:

(1) two GPS receivers (Trimble 7400MSi),

(2) four radio modens (TRIMTALK $900^{\mathrm{TM}}$ ),

(3) a Permanent Mount L1/L2 Geodetic antenna for Base Station,

(4) a Rugged L1/L2 GPS antenna for Rover,

(5) four radio/moden antennae,

(6) one PC with dual serial ports, and

(7) batteries, cables, and other accessories.

During the installation of GPS receivers, the installer must make sure that the receiver is mounted so that the environmental conditions in which the unit operates do not exceed specified capabilities. Excessive shock and vibration can cause both loss of satellite lock and physical damage to receiver. Therefore, it is 
necessary to make a safe and stable suitcase to contain the receivers in order to ensure the high-accuracy performance and avoid physical damage during the waste compaction operation. After installing the $7400 \mathrm{MSi}$ receivers and antennae, the interface cables can be routed around all devices. The cable routing depends on the product number and location of the devices connected to $7400 \mathrm{MSi}$ receiver. A connection scheme of GPS devices for a landfill operation is illustrated in Figure 6. One 7400MSi receiver is used for the base station, and another receiver is mounted on the compactor to perform a real-time positional data acquisition.

After the installation of GPS equipment, a Remote Control Software ${ }^{\mathrm{TM}}[15]$ is used to configure the $7400 \mathrm{MSi}$ receivers' setup. Before initialization, the $7400 \mathrm{MSi}$ provides float solution (meter-level positioning). Float solutions are differentially corrected positions relative to the base station. The initialization process is normally completed within 2 to 10 minutes. Once initialized, the position mode switches from float to fix solution, and the precision should drop from meterlevel to centimeter-level. TRIMTALK 900 radio modens are used for data communication among base station, GPS receiver on the compactor, and PC in the landfill office. Based on this system, the PC can incorporate real-time surface information into a 3-D GDS by receiving data from GPS.

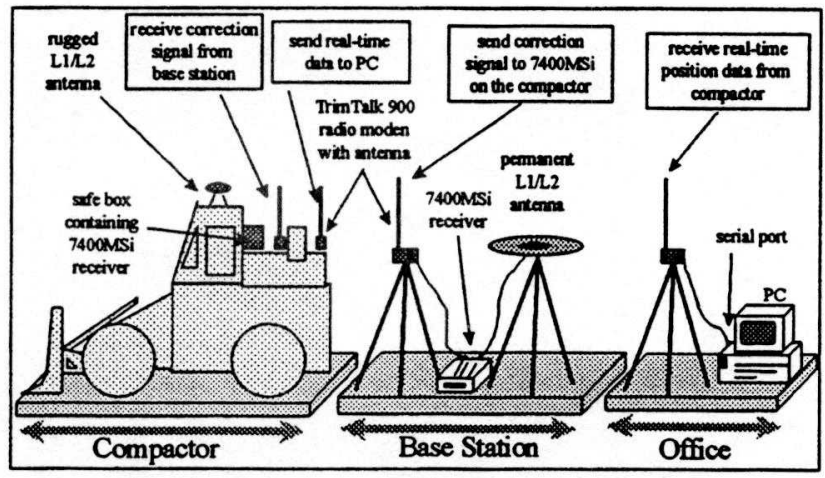

Figure 6: Configuration of GPS System

\subsection{Managing Landfill Space Using Octree Algorithm}

The landfill site can be partitioned into small working places called: cells and monominoes [6,7]. A cell is designed to contain the total amount of waste that can be compacted by one compactor in one working day. In order to make the daily operation manageable and efficient, the cell is divided into smaller working areas called monominoes whose dimensions depend on the turn radius of compactor. It is preferable to have the length and width of the cell equal for cover material minimization and ease of maintenance. A spatial partitioning strategy called Octree algorithm recursively divides the landfill site into $2^{\mathrm{m}} \times 2^{\mathrm{m}} \times 2^{\mathrm{m}}$ cells, and each cell into $2^{\mathrm{n}} \times 2^{\mathrm{n}} \times 2^{\mathrm{n}}$ monominoes. An octree is a hierarchical data structure that represents $3 \mathrm{D}$ volumetric information in an eight-way branching tree [16]. As shown in Figure 7, the space is represented by the root node in the form of a cube, which is then subdivided into eight octants to form the first level of the tree. Figure 8 demonstrates how to partition a typical landfill site into cells. The spatially partitioned configuration of the landfill site is stored using a octree data structure that is a variant of the octree (see Figure 11).

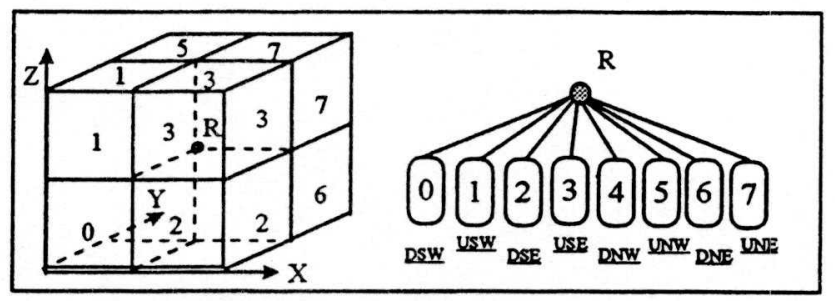

Figure 7: Octant Numbering

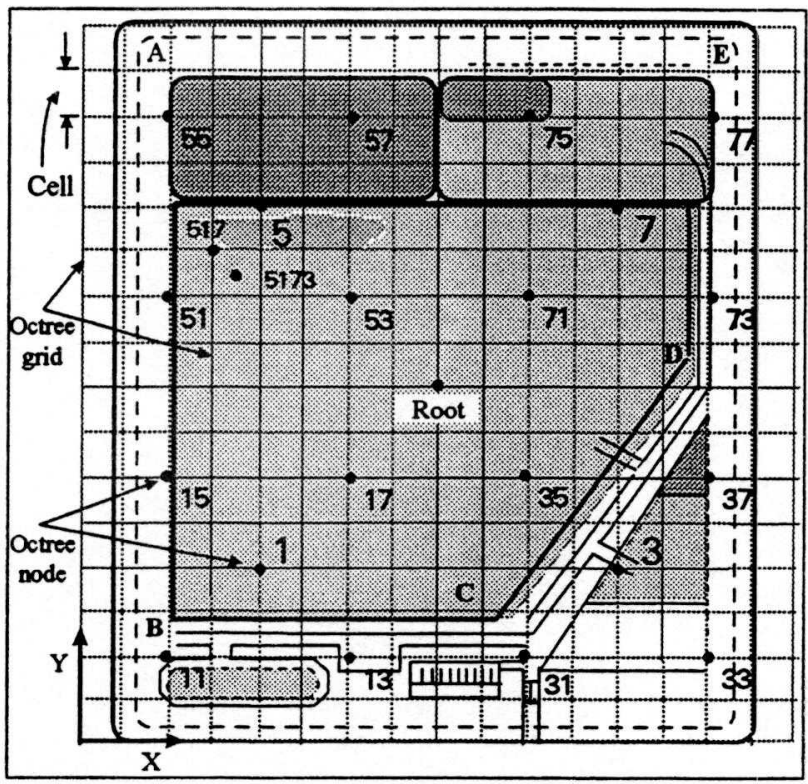

Figure 8: Partition a Landfill Site into Cells (top view)

Nodes that are not entirely occupied by the object are called partial or gray nodes. Each gray node is recursively subdivided into eight octants until all its descendent are either entirely disjoint from the object (empty or white nodes), completely occupied by the real object (full or black nodes) or virtual object (virtual or black-line nodes), or the desired resolution is achieved 
(see Figure 12). Virtual notes on the octree structure represent the random shape of landfill configuration.

There are three types of octree representation : the first is the regular octree, which uses explicit pointers to keep a spatial ordering of nodes in memory; the second is the linear octree, a pointerless allocation scheme which uses a linear key code to uniquely locate a node in the tree; and the third is based on the forest of trees.

This research employed the linear octree to 3-D GDS due to its space efficiency and simplicity of encoding and decoding of its nodes. In spatially decomposing a landfill site, the octree data structure partitions the landfill into small working areas. As shown in Figure 11, the entire data structure has three major levels: cell level, monomino level, and octant level. In cell level, the landfill site can be partitioned into cells using an octree structure (see Figure 8). The tiling of a cell is performed by monominoes whose dimensions depend on characteristics of the compactor and size of the landfill site (see Figure 9). The waste compaction within one monomino can be completed by three types of motion models: (1) Straight_Up, (2) Straight_Down, and (3) Zig_Zag [5,6,7,8]. Using Octree algorithm once again, one monomino can be divided into several octants (see Figure 10) by a dimension that is dependent on the height of one-pass compaction. Generally, the waste is spread in layers less than $0.61 \mathrm{~m}$ ( $2 \mathrm{ft}$ ) deep and is then compacted by a compactor. Therefore, the height for the cube of an octant would be less than $0.61 \mathrm{~m} * \cos \theta . \quad \theta$ is the slope angle of the working place.

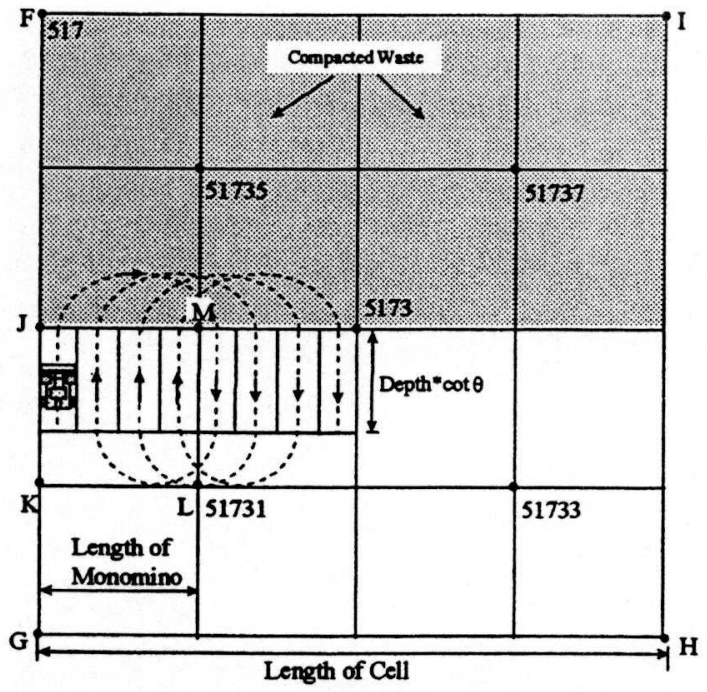

Figure 9: Partition a Cell into Monominoes (top view)

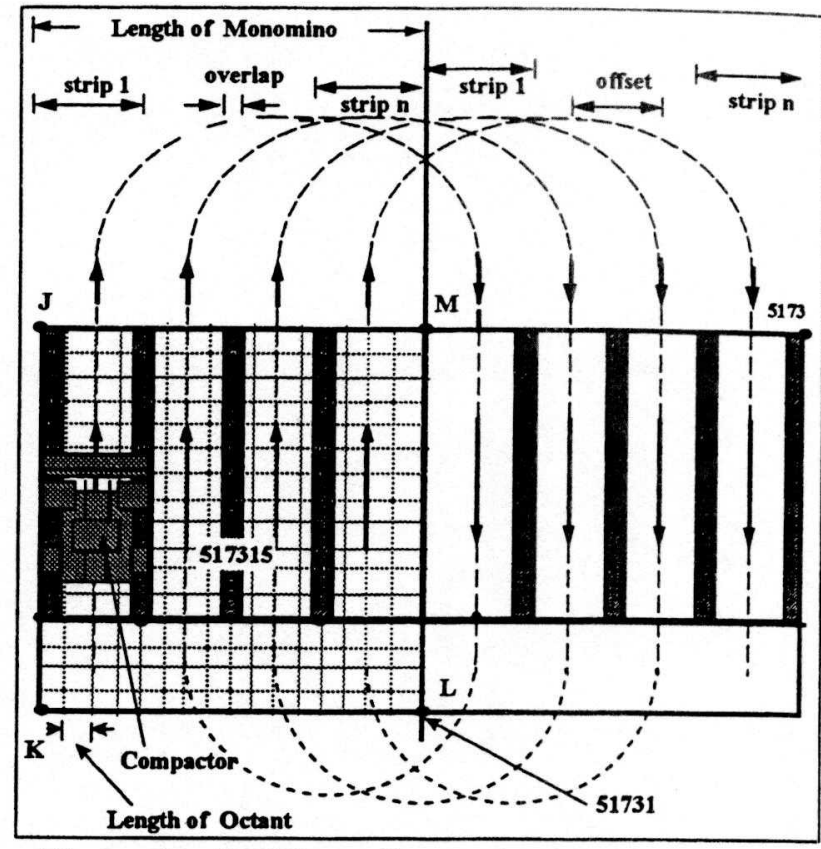

Figure 10: Partition a Monomino into Octant (top view)

Every octant has its coordinate according to the entire landfill configuration. Thus, when GPS installed on a compactor receive its exact location, the octant occupied by that compactor can be pointed out from a octree structure. Then, waste information can be stored in the octant that the compactor just pass through. The space usage of entire can be understood by monitoring the usage of octants. For instant, the empty space can be generated by calculating the total amount of empty octant (node's color is white). The total usage for coal ash can be generated by calculating the total amount of occupied octant (node's color is black and node's waste type is coal ash). Properties of Octant includes a node number, a waste type, a node location, a node color, dimensions, and directions to its children nodes (see Figure 12). Consequently, the space consumption can be instantaneously monitored using GPS linked with an octree data structure of a landfill site. 


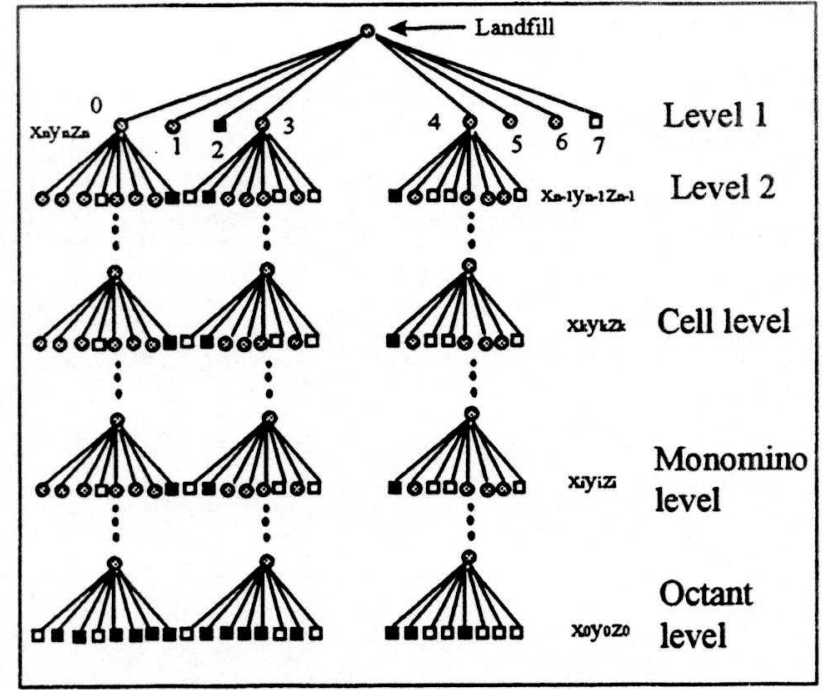

Figure 11: Octree Structure of an Entire Landfill

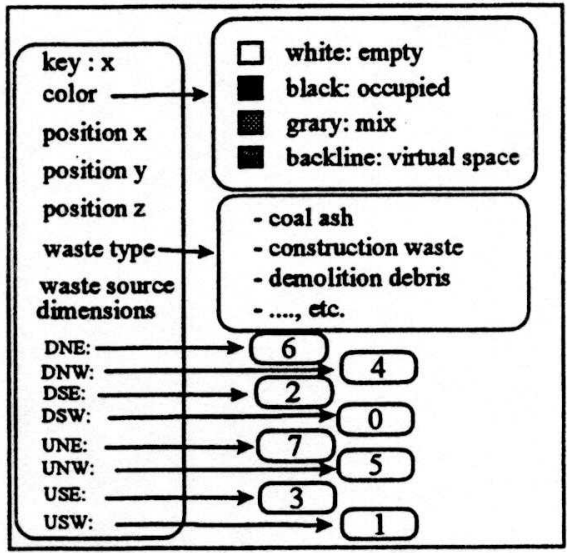

Figure 12: Properties of an Octant

\subsection{Octree Coding System [16]}

The methodology of encoding and decoding octree nodes is presented in this section. The octal locational code of a node's neighbor is easily inferred from its own locational code. Since performance of the octree algorithm depends on the efficiency of the neighbor finding procedures, a large portion of this section is devoted to the presentation of face, edge and corner adjacency primitives in linear octrees.

The difference between a regular octree and a linear octree lies only in their respective node encoding formats. The first encoding scheme allocates explicit pointers to keep a spatial ordering of nodes in the memory. In this representation, individual nodes are located by following a chain of pointers from the root to the desired node. Consequently, a large portion of the storage space is taken up by the partial nodes and their associated link fields.
The second encoding method, the linear octree, is a pointerless allocation technique. It is a space efficient encoding that does not store partial or empty nodes. Each terminal node is assigned a unique locational code corresponding to a sequence of directional codes which located a leaf along a path starting from the root of the tree. The list of all the locational codes is stored in ascending order, which in fact corresponds to a vertical (depth-first) traversal of the tree.

The octree shown in Figure 11 represents the recursive subdivision of the $3 \mathrm{D}$ object enclosed in a $2^{3} \times 2^{3} \times 2^{3}$ universe. As illustrated in Figure 7, the eight octants of each node are numbered from 0 to 7 by concatenating the $x_{i}, y_{i}$, and $z_{i}$ bits of the binary representations of the node coordinates $\mathrm{X}, \mathrm{Y}$, and $\mathrm{Z}$, respectively. The octal digit formed by $x_{i}, y_{i}, z_{i}$ indicated the position of the node within the $(n-i)^{\text {th }}$ subdivision of the universe. Thus, each black terminal node is encoded by an octal integer number in a weighted system where each digit represents the node location in each successive subdivision.

The above representation implicitly encodes the path from the root of the tree to the node using the following expression. For details discussions on octree algorithm, reader should refer to Samet [17] and Ibaroudene et al. [16].

$Q=\sum_{k=0}^{n-1} q_{k} 8^{k}=\sum_{k=0}^{n-1}\left(4 x_{k}+2 y_{k}+z_{k}\right) 8^{k}$

$Q$ is an integer number written in base 8 , and its digits $q_{k}$ represent the directional codes that map the path from the root of the tree to a particular voxel, when the universe space is recursively subdivided into octants.

The decoding operation represents the converse process of the procedure described in the previous section. In this case, the required task is to determine the $X, Y$, and $Z$ coordinates of part of an object enclosed in a $2^{\mathrm{n}} \times 2^{\mathrm{n}} \times 2^{\mathrm{n}}$ universe, given the octal locational code $Q$, and the resolution $\mathrm{n}$ of the dimensional axes.

\section{System Implementation}

The system is implemented with 3-D graphical interface software, which integrates GPS positioning technology equipment to allow instantaneous updating of a 3-D graphical database for landfill operations. The GPS equipment includes GPS receivers (Trimble $7400 \mathrm{msi}$ ), radio modems (TrimTalk 900), GPS antennas, supporting hardware, and software which facilitates the 3-D graphical database throughout construction operations. The 3-D software system for this project is implemented by using Microsoft Visual $\mathrm{C}++$ version 4.2 
linked with the OpenGL TM Utility (GLU) library. Some user-friendly features (i.e., Zoom-In, Zoom-out, Panover, and Rotation of objects) are provided in this program [18].

\section{Conclusions}

A 3-D GDS for landfill operations, incorporating state-of-the-art GPS positioning technology, was developed. This software system offers features of monitoring the space consumption for landfill operations in addition to record waste locations for project managers or foremen during the job-site operations. This paper presented the entire methodologies, including setup RTK GPS, processing GPS data, and developing an efficient geometric model.

\section{Acknowledgments}

The second author sincerely thanks the National Science Foundation Grant No. MSM-9058092, Presidential Young Investigator Award, for financial support of the research described herein. The authors also appreciate Mr. Edward J. Down (Trimble Navigation, Inc., Elgin, Illinois) for his support of providing the GPS equipment. The authors also would like to thank Mr. Peter O. Creamer (RMT, Inc., Madison, Wisconsin) for his input and suggestions. Special thanks to John R. Meier, a graduate student who helped at the end.

\section{References}

[1] Jaselskis, E.J., D'Silva, A.P., Flugrad, D., Vannette, M. and Zamzow, D. (1991) "Conceptual Robotic Soil Sampler Using Remote ICP-AES Technology," Proceedings, Conference on Hazardous Waste Research, Kansas State University, May 29-30, pp. 153-158.

[2] D'Silva, A. P., Zamzow, D., Jaselskis, E. J., and Weeks, S. (1992). "Remote, Real-time Analysis of Hazardous Waste Through Laser Ablation-Inductively Coupled Plasma-Atomic Emission Spectromoetry," Proceedings from Spectrum '92 Conference, International Topical Meeting on Nuclear and Hazardous Waste Management, Vol. 1, August 23-27, 1992, Boise, Idaho, pp. 409-413.

[3] Starr, G.P., Donohoe G.W., Wilson, D., and Kopalle, R.(1994). "Robotic Workcell for Waste Handling," In L. A. Demsetz and P. R. Klarer, editors, Robotics for Challenging Environments, American Society of Civil Engineering, 1994.

[4] Griffith, A. F., Haas, C. T., Tucker, R. L. (1994) "Feasibility Analysis of Automated Material Handling for Hazardous Waste Remediation," In L. A. Demsetz and P. R. Klarer, editors, Robotics for Challenging Environments, American Society of Civil Engineering,
1994.
[5] Tserng, H. P., (1994). "OPSALC: An Operations Planning System for an Autonomous landfill Compaction," M.S. Thesis, University of WisconsinMadison, Madison, WI.

[6] Tserng, H. P., Kunigahalli, R., and Russell, J. S., (1995). "OPSALC: An Operations Planning System for an Autonomous Landfill Compaction," Proceedings of Twelfth International Symposium on Automation and Robotics in Construction, May 31-June 2, Warszawa, Poland, pp. 63-69.

[7] Tsemg, H. P., Veeramani, D., Kunigahalli, R. and Russell, J. S., (1996). "OPSALC: A Computer-Integrated Operations Planning System for an Autonomous Landfill Compaction," International Journal of Automation in Construction, Amsterdam, The Netherlands, Volume 5, pp39-50.

[8] Tserng, H. P., Russell, J. S., Veeramani, D., and Kunigahalli, R., (1996). "A Motion Planning Software System for Automated Landfill Compaction on Rough Surfaces," Proceedings of 13th International Symposium on Automation and Robotics in Construction, June 11-13, Tokyo, Japan, pp305-413.

[9] Kunigahalli, R., Russell, J. S., and Tserng, H. P., (1995). "Motion Planning of an Autonomous Compactor in a Hazardous Landfill Site," Joumal of Microcomputer in Civil Engineering, Vol. 10, 339-355.

[10] Tchobanoglous, G., Theisen, H., and Eliassen, R., (1989). Solid Waste: Engineering Principles and Management Issues, McGraw-Hill, Inc., New York, N.Y.

[11] Koerner, R. M., (1993). "Collection and Removal Systems,". Geotechnical Practice for Waste Disposal Daniel (eds.), Chapman \& Hall, Inc., New York, NY.

[12] Lemar, T.S. and Thies, F., (1996). "Enlisting Satellites to Help Monitor landfill Air Space," Solid Waste Technologies, July/August, pp. 18-24.

[13] Trimble navigation Ltd., (1989). "GPS: A Guide to the Next Utility," Trimble navigation Ltd., Sunnyvale, CA.

[14] Trimble navigation Ltd., (1993). "Differential GPS Explained," Trimble navigation Ltd., Sunnyvale, CA.

[15] Trimble navigation Ltd., (1995). "7400MSi Operation Manual," Trimble navigation Ltd., Sunnyvale, CA.

[16] Ibaroudene, D., Demjanenko, V., Acharya, R.S., (1990). "Adjacency Algorithm for Linear Octree Nodes," Image and Vision Computing, Vol. 8., No. 2, pp. 115-123.

[17] Samet, H., (1990). Applications of Spatial Data Structure, Reading, MA: Addison-Wesley.

[18] Tserng, Hui-Ping, (1997). "Toward a framework for an Automated landfill system (ALS)," Ph.D. Thesis, University of Wisconsin-Madison, WI. 